\title{
Developing a Theory of the Strategic Core of Teams: A Role Composition Model of Team Performance
}

\author{
Stephen E. Humphrey \\ Pennsylvania State University
}

\author{
Frederick P. Morgeson \\ Michigan State University
}

\author{
Michael J. Mannor \\ University of Notre Dame
}

\begin{abstract}
Although numerous models of team performance have been articulated over the past 20 years, these models have primarily focused on the individual attribute approach to team composition. The authors utilized a role composition approach, which investigates how the characteristics of a set of role holders impact team effectiveness, to develop a theory of the strategic core of teams. Their theory suggests that certain team roles are most important for team performance and that the characteristics of the role holders in the "core" of the team are more important for overall team performance. This theory was tested in 778 teams drawn from 29 years of major league baseball (1974-2002). Results demonstrate that although high levels of experience and job-related skill are important predictors of team performance, the relationships between these constructs and team performance are significantly stronger when the characteristics are possessed by core role holders (as opposed to non-core role holders). Further, teams that invest more of their financial resources in these core roles are able to leverage such investments into significantly improved performance. These results have implications for team composition models, as they suggest a new method for considering individual contributions to a team's success that shifts the focus onto core roles.
\end{abstract}

Keywords: team, group, role, core, experience

Over the past 20 years, a considerable amount of research has been focused on identifying the range of factors that can lead to enhanced team performance (see Ilgen, Hollenbeck, Johnson, \& Jundt, 2005, for a review). This body of research has advanced our understanding of why some teams are more successful than others. Team-level research, however, presents some unique challenges when it is compared with individual-level research. For example, the conceptualization and measurement of constructs at collective levels of analysis require a consideration of emergent phenomena (typically arising from complex behavioral interactions) that have no lower level analogue. A considerable amount of research has sought to develop the conceptual and empirical frameworks needed address these challenges and to advance team level research (Chan, 1998; Klein, Dansereau, \& Hall, 1994; Kozlowski \& Klein, 2000; Morgeson \& Hofmann, 1999; Rousseau, 1985). One of the key issues identified by this research concerns the composition of collective level constructs.

Stephen E. Humphrey, Department of Management and Organization, Pennsylvania State University; Frederick P. Morgeson, Eli Broad Graduate School of Management, Michigan State University; Michael J. Mannor, Department of Management, University of Notre Dame.

We thank Don Conlon, John Hollenbeck, John Wagner, and Ann Marie Ryan (as well as the students in her PhD seminar) for their comments on an earlier draft of this article.

Correspondence concerning this article should be addressed to Stephen E. Humphrey, Smeal College of Business, Department of Management and Organization, Pennsylvania State University, University Park, PA 16802. E-mail: stephen.humphrey@psu.edu
Composition research has tended to focus on what could be termed "individual attribute composition." This approach explores how different ways of aggregating individual team member attributes relate to team effectiveness. For example, researchers have examined different ways to conceptualize team ability, such as the average level of ability across team members (e.g., Moon et al., 2004; Tziner \& Eden, 1985), the maximum or minimum ability of individual team members (e.g., Barrick, Stewart, Neubert, \& Mount, 1998; Williams \& Sternberg, 1988), or variation in ability among team members (e.g., Barrick et al., 1998; Miller, 2001). Although they are conceptualized and operationalized in different ways, all these forms of composition start with the notion that the individual attribute is the basic unit of analysis.

This approach has advanced our understanding of team performance, but there are other potentially useful ways in which to conceptualize team composition. Another approach, which can be termed "role composition," investigates how the characteristics of a set of role holders impact team effectiveness. Because roles typically are occupied by multiple individuals, role composition can be thought of as an important additional composition level. Roles are a fundamental feature of teams (Hackman, 1987), and the completion and synchronization of roles is necessary for effective performance (Steiner, 1972). Inclusion of a role level perspective in team models broadens our understanding of team behavior, as a role perspective focuses specifically on the tasks being performed in a team (Mumford, Van Iddekinge, Morgeson, \& Campion, 2008; Stewart, Fulmer, \& Barrick, 2005).

By shifting the focus from individual attribute composition, which deals with how the individual differences of team members 
impact team performance (see Bell, 2007; Chan, 1998; Harrison \& Klein, 2007), to role composition, which deals with how the characteristics of role holders impact team performance (e.g., when multiple individuals hold the same role; see Pearsall \& Ellis, 2006; Stewart et al., 2005), we can apply theories of individual differences to the roles being performed within a team. Essentially, the role composition perspective considers roles as collectives that subsume several team members but that are subsets of a team. Thus, we can draw from the literature on composition and compilation (Kozlowski \& Klein, 2000) to examine the impact of role holder characteristics on team behavior.

One significant implication of the role composition approach is that it allows us to identify the differential impact of various team roles on team effectiveness. Some studies have suggested that some roles in an organization are more critical to performance than are others (Delery \& Shaw, 2001; Emery \& Trist, 1969). That is, because of the unique exposure a role has to the problems encountered by a team (Emery \& Trist, 1969) or the competitive advantage a division confers to organizational performance (Delery \& Shaw, 2001), certain subsets of a collective can have a disproportional impact on the collective's performance.

We draw from this perspective on team roles to adopt a role composition approach and to introduce criteria for identifying a priori when a role is more strategically core to team effectiveness. We then draw from individual differences psychology to examine the impact of experience and job-related skill on team performance. We further propose that the experience and job-related skill of strategic core role holders is more strongly related to team performance than is the experience and job-related skill of noncore role holders. Finally, we hypothesize that increased investment into the core roles relative to other roles can effectively leverage the strategic core for improved performance.

\section{From Individual Attribute Composition to Role Composition}

Researchers have long struggled to understand the relationship between individuals and collectives (Morgeson \& Hofmann, 1999). Several researchers have presented models that discuss the theoretical relationship between individual and team-level constructs (e.g., House, Rousseau, \& Thomas-Hunt, 1995; Rousseau, 1985). Other researchers have presented theoretical guidelines for conceptualizing constructs and theories (e.g., Chan, 1998; Harrison \& Klein, 2007; Klein et al., 1994) or have utilized task dimensions to conceptualize individual attributes in teams (e.g., Barrick et al., 1998; LePine, Hollenbeck, Ilgen, \& Hedlund, 1997).

The crux of these approaches is an attempt to conceptualize collectives (e.g., teams) as aggregated collections of individuals. Because these approaches allow researchers to theorize about and empirically study a team's characteristics, processes, or performance by focusing on the characteristics or perceptions of individual team members, they provide insight into the teamwork context and team effectiveness. In fact, these models are crucial for the study of teams.

One weakness of these models, however, is that they treat teams as undifferentiated entities. This runs counter to what we know about teams, as even early research on teamwork described teams as a system of roles (Bales, 1950). A role is an expected pattern or set of behaviors interrelated with the behaviors of others (Biddle,
1979; Katz \& Kahn, 1978; Stewart et al., 2005); it is considered the key conceptual unit of the team (Ilgen et al., 2005), as action in teams is completed through role behaviors (Katz \& Kahn, 1978). The coordination and performance of team roles is necessary if the team is to avoid process loss and perform effectively (Steiner, 1972). Essentially, team performance is the amalgamation of the performance of a system of interconnected roles. Although one or more team members (i.e., the role holders) may perform a role in a given team, it is important to note that the behaviors and expectations of a role are generally defined externally to the role holders. Given the central place that roles hold in the performance of a team, it is critical to focus the level of theorizing on roles (Klein et al., 1994).

It is interesting that, although team research has predominantly followed the individual attribute composition approach, most models of team performance are based on one of two implicit assumptions: (a) all team members are performing the same role in a team (i.e., there is no team role differentiation) or (b) all of the team roles have the same impact on team performance. Yet, the first assumption is typically not true, as teams often possess differentiated role structures (Belbin, 1993; Mumford, Campion, \& Morgeson, 2006; Mumford et al., 2008) in which there is some degree of specialization, independence, and autonomy of roles within a work team in relation to other roles in a work team (Lawrence \& Lorsch, 1969). In fact, the need to differentiate roles is often the primary reason for creating a team. For example, surgical teams are specifically designed so one role performs the surgical procedures (e.g., makes incisions), one role provides support to the surgeon role (e.g., provides requested surgical equipment, monitors blood pressure), and one role provides and monitors anesthesia. Although the team could be structured without role differentiation (i.e., all team members would perform surgical operations, monitor blood pressure, and provide anesthesia), it either would be composed of individuals who possessed all of the requisite skills or would be expected to perform inefficiently (Hollenbeck et al., 2002).

Teams typically have differentiated role structures, but there has been little discussion of the importance of roles. Yet there is reason to believe that the second implicit assumption in the teams literature (i.e., all roles have the same impact on team performance) is incorrect. Systems of roles are often designed such that one role is more tightly linked to the overall performance of the team than are other roles. Consider a new product development team. One role in the team could be responsible for producing consumer research, brainstorming an innovative product, engineering the product, and testing the product, whereas a second role might be responsible only for managing the team's financial resources. In this case, the first role is likely to be more critical for the overall success of the team.

Researchers have made similar distinctions at other organizational levels regarding the differential impact of a subset of a collective on the whole (e.g., Barney, 1991). For example, Huselid, Beatty, and Becker (2005) argued that the focus should be on putting the best human capital into "A positions," specifically, positions that are most important for executing firm strategy. Similarly, Delery and Shaw (2001) argued that differences in what people do in an organization (e.g., human resource management vs. production vs. marketing) have a differential impact on the performance of the collective 
organization. Delery and Shaw suggested that organizational success is not predicated on the high performance of all members. Rather, success in a strategic core of the workforce can produce and maintain above-industry profits.

Whereas existing literature has primarily discussed the importance of different roles in organizational performance, we expect that these ideas are relevant to teams. That is, we expect that certain roles are more strategically core (i.e., more critical) for overall team performance.

\section{Defining the Strategic Core}

The next step is determining how to identify the most important roles. Prior definitions of a strategic core at other levels would suggest that a strategic core role is the subset of the team that has the greatest impact on performance. This approach is problematic, however, as it allows only for the post hoc identification of a strategic core role and thus creates a tautological argument.

We have developed a definition of the strategic core that is independent of team performance and have thus avoided the tautological arguments. Drawing from sociotechnical and team design literatures, we define the strategic core as the role or roles on a team that (a) encounter more of the problems that need to be overcome in the team, (b) have a greater exposure to the tasks that the team is performing, and (c) are more central to the workflow of the team. As the components of the definition range in intensity (e.g., a role may encounter none, some, or even all of the problems), a strategic core role can be thought of as a continuum: The more that a role meets these criteria, the more "core" the role is to the team.

First, one role may encounter more of the problems (i.e., variance in sociotechnical terms) that need to be overcome (Barker, 1993; Emery \& Trist 1969). Cummings (1978) noted that an important goal when developing work teams is to provide them with the ability to resolve these problems. The problems may stem from boundary-spanning issues (i.e., information or resources entering or leaving the team; interactions with external constituency, such as customers; Ancona \& Caldwell, 1992) or issues concerning the creation of a team's output (Cummings, 1978). Regardless of the source of the problems, a team must overcome them to be successful.

For instance, in many production and service teams, interacting with and addressing customer complaints is essential for a team's success. The most important problems the team will face (e.g., failure to meet customer requirements, missed deadlines) have their origin in the customer base. Effective performance of this boundary-spanning role is essential for the team's success. If this role is not performed successfully and the problems emanating from the customer base are not adequately addressed, the team will fail.

Consider the operator role in a printing team. In a printing team, some team members load paper rolls, others replace cutting blades, and others monitor printed output. As the operator role is responsible for controlling the operation of the printing press and must adjust the press if any problems occur during the printing process, this role is core to printing teams. Obviously, problems in other roles may impact the performance of the team (e.g., the team may not have any paper to load), and we do not suggest that the other roles are unimportant for team performance. However, at any given time, one of the roles may encounter relatively more of the problems than do other roles. For example, in any given day the operator may have to face a multitude of problems, including misfed paper, dull cutting blades, and irregularities in color separation, all of which require direct action. In contrast, another role, such as the paper loader, may encounter a problem only once a month (e.g., there is no paper due to a delay caused by a hurricane).

Second, a particular role is more core than other roles if it has a greater exposure to the tasks that the team is performing. In effect, some role holders may have greater responsibilities within the team (Moon et al., 2004). Researchers have noted that work may be designed such that a role is responsible for performing a multitude of tasks or relatively few tasks (Humphrey, Nahrgang, \& Morgeson, 2007). Those roles that perform more tasks or complete more of the work will make the greatest contribution toward team goal achievement.

For instance, a team may have four roles that need to be filled. One role may be responsible for handling over $50 \%$ of the work, whereas the other three roles together are responsible for less than $50 \%$ of the total work. If the first role is not completed, the workflow chain is disrupted (Brass, 1984) and the result is low overall team performance (Pearsall \& Ellis, 2006). Thus, the heavily loaded task-oriented role is core to the team's performance specifically because of the role's greater contribution to the achievement of team goals.

Consider the programming role in a software development team. Although designers and architects perform valuable pieces of the software development process, it is the programming role that does the greatest amount of work on a project. As noted by Keil, Mann, and Rai (2000), the inability of programmers to complete their work has resulted in a large percentage of software projects being completed at a higher cost and with fewer features than projected.

Third, one role may be more central to the workflow of the team. Centrality can be defined as how connected a role is to other roles in a team (Sparrowe, Liden, Wayne, \& Kraimer, 2001). In sociological terms, tangible and intangible resources flow between nodes (which can be an individual or, in this case, a role), and nodes are connected to other nodes in a network. Centrality represents how connected a given node is to other roles. Centrality has generally been conceptualized in terms of betweenness and closeness (Freeman, 1979; Friedkin, 1991). Betweenness represents the number of paths between roles that pass through a specific role. That is, if a role serves as a hub for resources (i.e., all resources must pass through the hands of the focal role), it is high on betweenness. Closeness represents the distance of the focal role from all other roles (i.e., how connected an individual role is to all other roles). If a role is close to other roles, it is expected to receive information and resources more quickly than is a more distant role. Because tangible and intangible resources tend to flow through roles high in centrality, failure to complete these roles can leave the team without information or resources that are critical for its performance.

Finally, it is important to recognize that team performance is multifaceted. In any given team, multiple outcomes may be relevant (e.g., speed, accuracy, helping; Bachrach, Bendoly, \& Podsakoff, 2001; Beersma et al., 2003), and different tasks or workflows may impact these various outcomes. It is important to be clear about what dimension of performance is important for the 
team. Once this is accomplished, our definition can be used to identify a priori which role or roles are most strategically core. In our study, we focus broadly on overall team performance rather than one of the narrower dimensions.

\section{Team Member Experience and Job-Related Skill: The Raw Material of Team Role Performance}

The preceding discussion makes the distinction between core and non-core roles within a team by focusing on the general roles performed by different team members. To investigate the degree to which core roles are more important for the achievement of highly effective teams, we must understand what enables a team (specifically, the team members performing the roles) to achieve high levels of performance. Research has noted that the behavior and performance of the team are influenced by the composition of its members (e.g., Humphrey, Hollenbeck, Meyer, \& Ilgen, 2002; Kim, 1997; LePine et al., 1997). Moreover, recent research has suggested that the characteristics of role holders influence behaviors within roles (Stewart et al., 2005). Two significant influences are the range of past experiences the team members have had and the job-related skill a team member has to effectively perform the tasks associated with his or her individual role (Hunter \& Hunter 1984; Quiñones, Ford, \& Teachout, 1995).

In the following section, we present both an individual attribute composition hypothesis, in which we predict a team-level effect of the individual attribute on team effectiveness, and a role composition hypothesis, in which we predict that the attribute matters more for team effectiveness when it is possessed by strategically core role holders. This dual approach allows us to postulate the impact of compositional characteristics on team performance and, when we change the focus to the role level, to clarify the source of the team-level relationship.

\section{Experience}

Experience is a multifaceted construct (Quiñones et al., 1995) that can impact performance either directly or indirectly. The direct effect derives from the task-relevant knowledge that individuals can gain via experience at a particular task (Schmidt, Hunter, \& Outerbridge, 1986). This knowledge can be directly applied to future task performance, as it relates to the ability of a person to perform the task efficiently and accurately. That is, through experience, people learn the easiest way to perform the task, the things to avoid when performing the task, or the individual they need to work with to perform it. The indirect effect occurs because the knowledge gained through experience can be shared, such that more experienced team members can help less experienced members learn to perform better in their job.

Experience has been shown to impact both individual job performance (Schmidt \& Hunter, 1998) and team job performance (Berman, Down, \& Hill, 2002; Gladstein, 1984; Hollenbeck et al., 1995; Mohammed, Mathieu, \& Bartlett, 2002; Rentsch \& Klimoski, 2001). Yet, these effects have been observed in research that lacked "any guiding theoretical framework" (Tesluk \& Jacobs, 1998; p. 322) and resulted in confounded or otherwise deficient measures of experience. Fortunately, recent research has helped expand our conception of work experience (Tesluk \& Jacobs 1998) by suggesting that there are at least two aspects of experience that are important for team success.

\section{Career Experience}

Career or industry experience has been investigated at the individual level (Lance \& Bennett, 2000) and the team level (Gladstein, 1984). Career experience can be thought of as the length of time spent in a specific field and the number of times that tasks have been performed in that field (Tesluk \& Jacobs, 1998). In general, career experience contributes to team member performance through its development of expertise about the job or role (see Schmidt et al., 1986). High levels of career experience help performance in two ways. First, team members with higher levels of career experience have greater knowledge of how to perform the team task efficiently and effectively (i.e., tacit knowledge; Berman et al., 2002). Tacit knowledge reflects information acquired free from direct instruction and has a large impact on the difference between below average and above average performers (Wegner, 1986). For example, it might reflect an individual team member's development of shortcuts for the work or another's knowledge of how to best structure the work. In a team, the members can share the knowledge that their experiences have created among each other. Thus, the team benefits when any individual gains job knowledge through greater career experience.

Second, higher levels of career experience make it more likely that members of the team will know how to respond when infrequent events occur. Individual team members may have had unique experiences outside of a specific team that have resulted in the development of tacit knowledge. By tapping into and drawing from the collective experience, however, the team will be able to formulate an appropriate response to the infrequently occurring event. Thus, teams that have an overall higher level of career experience will likely be better performers.

Whereas the previous argument is derived from an individual attribute composition perspective, the role composition perspective suggests that we also should examine the impact of specific roles on team performance. More specifically, the strategic core perspective suggests that strategic core roles are more critical for team performance than are non-core roles. Combining the strategic core role logic with the logic underlying the proposed relationship between career experience and team performance, we expected that teams would perform better if the strategic core role holders possessed higher levels of career experience.

This proposed relationship does not negate the main effect relationship between overall team career experience and team performance. We expected that the characteristics of non-core role holders would still impact team performance: Career experience matters for all roles. However, we expected that the characteristics of core role holders would have a comparatively greater impact on team performance than would the characteristics of non-core role holders.

Hypothesis 1A: Teams with higher levels of career experience will have higher levels of overall team performance.

Hypothesis 1B: The career experience of core role holders will be more strongly related to overall team performance than will the career experience of non-core role holders. 


\section{Team Experience}

Team experience is the best studied team-level experience construct. It represents the quantity of time continuously spent with the current team. Team experience should facilitate team performance in three ways. First, as team members have greater experience with the team, they are able to develop shared mental models (Kim, 1997). Teams that possess shared mental models perform better, due to superior coordination and helping behaviors (Mathieu, Heffner, Goodwin, Salas, \& Cannon-Bowers, 2000).

Second, greater experience can lead to higher levels of transactive memory. Whereas shared mental models represent only the knowledge shared by all team members, transactive memory reflects both the knowledge possessed by individual team members and the awareness of who possesses that knowledge (Austin, 2003; Wegner, 1986). That is, transactive memory represents knowledge about who in the team has specific knowledge. With increased experience, teams form a consensus on who possesses specific knowledge (Bunderson, 2003), the redundancy of the knowledge across the team, and the volume of knowledge actually possessed. This self-knowledge allows the team to tap relevant knowledge efficiently, when necessary (e.g., to perform aspects of tasks that some members of the team cannot perform, Berman et al., 2002), and to produce high levels of performance (Austin, 2003; K. Lewis, 2003).

Third, as individuals increase their team experience, they will likely learn more about the roles of other team members. This understanding will produce a greater understanding of their own role and how their role fits with those of others. Such knowledge should positively impact team performance (Abramis, 1994), because the individuals can more effectively communicate what each member contributes to the team (Salas, Rozell, Mullen, \& Driskell, 1999) and what is expected of them in return (Seers, Petty, \& Cashman, 1995). That is, the team will determine which roles are filled by each team member (Tuckman, 1965), which will lead to effective team performance. This proposed process suggests that higher levels of overall team experience would be related to higher performance. If team experience is important for team performance and core roles are more important for team performance, the team experience possessed by core role holders would more strongly impact team performance than would the level of team experience possessed by non-core role holders.

Hypothesis 2A: Teams with higher levels of team experience will have higher levels of overall team performance.

Hypothesis 2B: The team experience of core role holders will be more strongly related to overall team performance than will the team experience of non-core role holders.

\section{Job-Related Skill}

In addition to these aspects of experience, the job-related skill of team members plays an important role in team performance. As noted by Morgeson, Delaney-Klinger, and Hemingway (2005), "Job incumbents possess a given level of skill that is directly relevant to the specific tasks they perform at work" (p. 400). This skill level does not overlap heavily with cognitive ability or job experience (Morgeson et al., 2005; Schmidt \& Hunter, 1998) but instead represents the specific ability of a job incumbent to per- form those tasks inherent in his or her job (Humphrey, Nahrgang, \& Morgeson, 2007).

As noted by Sundstrom, de Meuse, and Futrell (1990), most teams require experts in a specialized area who are both knowledgeable of and skilled at performing specific tasks. As opposed to general cognitive ability, which affects performance through its development of job knowledge (Hunter \& Hunter, 1984), jobrelated skill is expected to impact performance because it directly reflects the ability to perform specific tasks. Job-related skill consists of a variety of knowledge, skills, and abilities, including procedural and declarative knowledge, task skills, and physical abilities (Neuman \& Wright, 1999; Tziner \& Eden, 1985). Thus, job-related skill encompasses the knowledge and skill required to perform task-specific behaviors.

There is reason to suspect that job-related skill has a large impact on task performance. Schmidt and Hunter (1998) found that work sample tests were among the best predictors of job performance beyond general mental ability. In fact, Hunter and Hunter (1984) specifically stated that work sample tests are the best predictors of job performance for people currently on the job.

Although job-related skill is less studied in a team context, there is reason to suspect that it matters in teams. For example, Tziner and Eden (1985) found that uniformly low skilled teams performed much worse than expected on the basis of the individual jobrelated skill of each team member, whereas uniformly high skilled teams performed much better than expected. They suggested that a uniformly low skilled team would produce interpersonal conflict as a result of unfilled role expectations and the negative feedback resulting from low team performance, whereas highly skilled teams could capitalize on synergies to produce high performance. Moreover, Neuman and Wright (1999) showed that work sample measures are significant predictors of team performance. In action teams, Klein, Ziegert, Knight, and Xiao (2006) found that active leadership is delegated in part due to whether the junior member of the team has high levels of job-related skill or whether the senior team member has high enough levels of job-related skill to correct mistakes made by the junior member.

Once again, we expected that the characteristics of strategic core role holders would be more influential on team performance than would the characteristics of non-core role holders. Thus, the jobrelated skill of core role holders should be more strongly related to team performance than should the job-related skill of non-core role holders.

Hypothesis 3A: Teams with higher levels of job-related skill will have higher levels of overall team performance.

Hypothesis 3B: The job-related skill of core role holders will be more strongly related to overall team performance than will the job-related skill of non-core role holders.

\section{Leveraging the Strategic Core for Competitive Advantage}

Following from the argument that strategic core roles have a disproportionate relationship with performance, teams that invest more heavily in filling strategic core roles with experienced and high-skill individuals should be likely to outperform teams that do not make such leveraged investments. Teams that invest financial resources equally across core and non-core team roles are, in 
essence, allocating their resources inefficiently. Instead, organizations that use their knowledge of core roles strategically and direct a larger portion of their investments into the core should be able to reach higher levels of performance, as the most critical team roles will be better staffed (Huselid et al., 2005). Reflecting this logic, Delery and Shaw (2001) argued that the costs of investing resources in the non-core components of an organization will be "equal to or greater than the benefits obtained" (p. 179), specifically because the non-core functions do not contribute as much value to the organization. If a strategic core is critical for team performance, it is important that this role is staffed with higher quality workers. This goal can be accomplished by spending more money to hire better quality employees to perform these roles (Delery \& Shaw, 2001) and thus leveraging the roles to achieve improved performance.

Hypothesis 4: Teams with higher levels of resource allocation in core roles will have higher levels of overall team performance.

\section{Method}

\section{Setting}

We chose major league baseball as the setting in which to study our hypothesized relationships. Baseball is a team sport, in which a team of 25 players competes against another team. At any given time, only 9 team members are actively participating in the competition, though other team members may be substituted in at any time. Each team competes in 162 games during the season (the unit of time analyzed in this study). In each game, there are nine innings. Within an inning, each team has the opportunity to attempt to score runs (i.e., accumulate points for the team by having a player touch all four bases) and to prevent the other team from scoring runs. The team that has scored more runs at the end of the nine innings is the winner.

There were several reasons for choosing baseball as the setting for our study. First, sports teams have objective and easily interpretable performance measures (Pfeffer \& Davis-Blake, 1986; Wolfe et al., 2005), and this avoids problems associated with perceptual measures of team performance. Second, because baseball has public and wide appeal, a considerable amount of objective data, measured accurately and precisely, is available on the key study constructs (Goff \& Tollison, 1990). Third, Keidel (1987) has suggested that the lessons learned about sports teams transfer to organizational teams, as the interdependence within baseball teams and the attendant coordination demands have distinct implications for the study of teams in general. In fact, other organizational scholars have successfully studied organizational phenomena in the context of sports teams (e.g., Hofmann, Jacobs, \& Gerras, 1992; Staw \& Hoang, 1995). Fourth, baseball provides a good setting for testing our theoretical arguments (Wolfe et al., 2005), as there is a clear difference between core and non-core role holders. Finally, according to Sundstrom et al.'s (1990) typology, a baseball team is an action team, which is a team in which there is high differentiation (i.e., high specialization and exclusive membership in the team) and brief performance episodes that are repeated frequently. Such teams are commonly found in organizational settings.

\section{Sample}

We used data from major league baseball teams from 1974 to 2002 to test the hypotheses. This 29-year period was chosen because 1974 marked the start of free agency in baseball; the practice dramatically changed the movement of players and brought an attendant influence on the experience and skill composition of teams. The resulting pooled and cross-sectional data set included 778 observations. We obtained data from the Baseball Archive (Lahman, 2004) and Retrosheet (2004), which are comprehensive guides to team and game-level data. As noted by others who have used data from the baseball context (Hofmann et al., 1992), baseball teams consist of two distinct groups: pitchers and position players. Because the statistics of pitchers and position players are not directly comparable and because individual pitchers play in fewer games each year than do position players, all variables were standardized prior to analysis.

\section{Measures}

Operationalizing the strategic core of the team. The team's strategic core is the subset of the team in which the role encounters more of the problems facing the team, handles more of the work than do other roles, and is central to the workflow of the team. In determining which role can appropriately be categorized as the core, we needed to determine which role fulfills these criteria for this study. First, regarding the handling of work, all plays run directly through the pitching and catching positions. That is, a pitcher initiates every action within a game, which is preceded by the catcher "calling" the specific action to be performed (i.e., which pitch is to be thrown). On some plays, the pitcher and the catcher are the only players to act (i.e., the pitcher throws the ball, the catcher catches the ball, and the batter does not swing at it). In contrast, up to nine team members could each perform some action on another play. Regardless of how a play develops, the pitcher and catcher are both involved at the beginning, whereas no other player is guaranteed to be involved. Thus, the pitching and catching roles handle more work than do other roles. Second, considerable variance in performance occurs as a function of which pitch is called (via the catcher) and thrown, as no other position initiates action. A pitcher who throws an easily hittable pitch has created a situation that decreases the chance his team will win, whereas a pitcher who throws a difficult-to-hit "strike" increases the chance his team will win. Third, the pitcher and catcher serve as the hub of communication in the playing field. That is, a manager may call specific pitches (or a pitchout) from the dugout, which are communicated to the pitcher via the catcher. Alternately, a manager (or pitching coach) may meet with the catcher and pitcher at the pitching mound. At this point, the pitcher and catcher may communicate changes to the rest of the team. In this case, the pitcher and the catcher do not have exceptionally high levels of centrality but are higher on centrality than any of the other roles in the team.

This analysis suggests that the pitching and catching roles are the strategic core of the team. Thus, we defined the strategic core of the team as the pitcher and catcher roles.

Career experience. Career experience represents the quantity of experience. It was operationalized as the combination of the number of games played and either at bats (for position players) or innings pitched (for pitchers). This combination reflected both the 
volume and depth of career experience. ${ }^{1}$ Individually, the two variables are highly related $(r=.85)$. As with all of our experience measures, career experience was composed to reflect the amount of experience possessed at the beginning of the season. In addition, all variables were coded such that high numbers indicated higher levels of the relevant construct.

Team experience. Team experience represents the amount of experience with the current team. We operationalized team experience two ways. First, we created a variable called team experience average that was calculated as the number of continuous years each player had been with the focal team. Second, we created a variable called team experience $S D$ by calculating the standard deviation of the already calculated team experience average variable. The average variable can be conceptualized as a quantity variable that represents how much experience each team member has with the team. In contrast, the $S D$ variable captures whether team members have comparable amounts of experience on the team (regardless of the mean).

Job-related skill. Job-related skill represents the specific skill needed for a task. As noted previously, a strength of using baseball for hypothesis testing is that there are a large number of objective metrics. However, a downside is that there is an overabundance of metrics without a clear consensus on the best ways of measuring job-related skill. The classically studied metrics are batting average (for batters) and earned run average (for pitchers). However, over the past 2 decades, researchers and statisticians have developed numerous and more complicated metrics. For example, some teams now rely on indices such as batting average against, batting average with balls in play, slugging percentage, isolated power, runs created, equivalent average, and win shares to assess individual and team performance (James \& Henzler, 2002; M. Lewis, 2003). As there is not a consensus on the best metrics (and many of these metrics are highly related), we chose to operationalize job-related skill using a rate statistic and a measure of defensive skill. First, we chose two rate statistics that draw from both traditional and novel approaches to the conceptualization of skill: on-base percentage for and on-base percentage against. The first measure reflects a position player's skill in reaching base successfully, whether from a hit, a walk, or a hit by pitch. The second possibility reflects a pitcher's skill in preventing a batter from reaching base. These measures are similar in form and represent similar skills (i.e., the attainment or prevention of players getting on base). In addition, they are consistent with the classically studied baseball metrics. For example, on-base percentage against is highly correlated with earned run average $(r=.69$ in our data set). ${ }^{2}$ Finally, they are metrics that are mostly independent of what other team members do. For example, the capability of a position player to score runs is highly contingent upon what other team members do, which means that runs scored better reflects performance than job-related skill. In contrast, reaching base safely (i.e., on-base percentage) generally occurs independently of other team member actions.

Second, we used a measure of errors to capture defensive skill. In baseball, an error is awarded by the official scorekeeper when a player does not successfully complete a task that would normally have been completed, given an ordinary amount of effort by the player. We converted this metric to a rate statistic by dividing the number of errors by the number of games played (for position players) or the number of innings pitched (for pitchers).
Each score was standardized, and both on-base percentage against and the error rate were coded such that higher scores represented higher levels of job-related skill. We then averaged them together into one measure of job-related skill. Because current skill (i.e., current individual performance) may be partially related to and a function of current team performance, we used a 1-year lag (i.e., from the previous season), which provides a good approximation of the skill level of a player without being influenced by the team's performance in the focal season. If a team member had not played in the majors the previous season, his data were treated as missing and the team and role skill measure was created by averaging the data for the remainder of the team.

Core resource allocation. The allocation of resources to the strategic core was calculated by summing the salary of all of the players who filled the core role (i.e., all pitchers and catchers). However, as major league baseball did not release all of the players' salaries until 1985, this variable was calculated for the period 1985-2002 only. This resulted in a reduced sample of 498 teams for all analyses with this variable (core role, $M=$ $15,321,070, S D=11,102,137$; non-core role, $M=17,220,015$, $S D=11,707,548)$.

Team performance. The dependent variable was team performance. The most commonly accepted measure of team performance in major league baseball, as well as most professional sports, is team winning percentage (Kahn, 1993). Baseball performance can be conceptualized through its component parts (e.g., runs scored or runs allowed), statistical estimates of performance (James, 1982), or related concepts (e.g., attendance or profit). However, these measures either lack the completeness of winning percentage or are less intrinsically meaningful to the teams, players, or fans than is actual winning percentage.

As baseball teams play 162 games during a season, there are essentially 162 dichotomous evaluations of performance. Combining these 162 performance evaluations into one global measure

\footnotetext{
${ }^{1}$ There is reason to suspect that this relationship may be curvilinear, as individual-level research has indicated that there is a decreasing relationship between experience and individual performance as level of experience increases (McDaniel, Schmidt, \& Hunter, 1988). However, we do not believe that this is an issue at the team level. First, because the experience of a number of team members is averaged, it is hard to reach very high levels of team-level experience. Second, due to the dynamic and selfcorrecting nature of teams, low performers will eventually be excised from the team. Therefore, the team members with high individual experience will exert only a short-term and small-magnitude negative effect on the team. Third, there is empirical evidence that the relationship is very small in teams. For example, Berman et al. (2002) found a curvilinear relationship between team experience and team performance. However, they noted that this was only a small effect and that "only a handful of teams ... may have encountered this problem" (Berman et al., 2002, p. 23). Having combined this information, we believe that, in practice, teams either will not experience the diminishing returns associated with individual experience or will encounter only a minimal negative impact that can be quickly corrected.

${ }^{2}$ Although we chose to use on-base percentage for and on-base percentage against as our measures of job-related skill, we tested our hypotheses by using on-base percentage plus slugging percentage for batters (following recent arguments for its validity; see M. Lewis, 2003) and earned run average for pitchers. The use of either (or both) of these alternate measures of job-related skill did not meaningfully change our results.
} 
creates a highly reliable estimate of performance. Thus, performance was operationalized at the season level, rather than at the game level.

League. Baseball teams compete in one of two leagues (American and National). These leagues have slightly different rules (e.g., the pitchers in the American League do not bat) and norms (e.g., prior to 2003, the strike zones were informally slightly different, depending on league). To eliminate these and any other differences, we statistically controlled for league in our analyses. League was dummy coded such that American League $=0$ and National League $=1$.

\section{Analytic Methods}

All experience and job-related skill measures were aggregated to the role (i.e., core/non-core) or team level, depending on the analysis. Our data were hierarchically structured, with multiple season-level performance outcomes for each team. This approach introduces the potential concern that there is dependence in our data caused by analyzing the same team over multiple time periods. There are several ways to address this concern, ranging from testing for autocorrelation in ordinary least squares regression to modeling the potential dependence using hierarchical linear modeling (HLM). As HLM "provides the correct parameter estimates and significance tests for multilevel and nonindependent data by estimating within-team and between-team variances and covariances separately, and by using the correct standard errors" (Chen, Kirkman, Kanfer, Allen, \& Rosen, 2007, p. 337), we chose to test our hypotheses using HLM.

The data was structured such that season-specific team characteristics (e.g., job-related skill) and performance were assigned to Level 1, whereas the team was assigned to Level 2. We tested our hypotheses using MLwiN Version 2.02 (Rasbash, Steele, Browne, $\&$ Prosser, 2004). To facilitate comparability of the various experience and job-related skill measures, we standardized all measures, which means that all parameter estimates essentially reflect standardized (beta) coefficients (Chen, Bliese, \& Mathieu, 2005). This process essentially grand mean centered all variables, as is consistent with HLM conventions.

We present a series of models of different relationships in Tables 2 and 3. For each model, we present the coefficients and standard errors for all parameters in the model. In addition, we present the variance at each level (season and team) for each model and compare the total variance for the model to the null model. This information, when coupled with the likelihood ratio test, allows one to determine the explanatory value of a particular model and effect size associated with the addition of specific parameters. Finally, given the directional nature of our hypotheses, we utilized one-tailed tests of significance levels.

\section{Results}

Table 1 presents the correlation matrix for the variables of interest. As shown in the table, the correlation between job-related skill and the experience constructs ranged from .22 to .30 .

Given the hierarchical nature of our data, we first calculated the null model for performance (Raudenbush \& Bryk, 2002). As shown in Table $2,8 \%$ of the total variance in team performance is attributable to team-level phenomena beyond any specific season. It is not surprising that some variance is attributable to an organization, as certain teams have been more (or less) successful across time. However, the low percentage of variance attributable to the team level suggests that the determinants of team performance in any given season are almost exclusively a function of season-level characteristics (such as team composition).

Our first set of hypotheses suggested that career experience, team experience, and job-related skill would all be related to higher levels of team performance. As shown in Models 3-5 in Table 2, each of the experience and job-related skill characteristics significantly predicted team performance. More specifically, career experience $\left(\beta=.452, \Delta R^{2}=.22, p<.05\right)$ and job-related skill $\left(\beta=.347, \Delta R^{2}=.14, p<.05\right)$ independently influenced team performance, which supported Hypotheses $1 \mathrm{~A}$ and $3 \mathrm{~A}$. Turning to team experience, we found that team experience $S D$ was negatively related to performance (i.e., more variance on team experience was bad for the team; $\beta=-.062$ ), whereas team experience average was positively related to performance (i.e., high mean levels of team experience were good for the team; $\beta=$ $\left..378, \Delta R^{2}=.12, p<.05\right)$, which supported Hypothesis $2 \mathrm{~A}$. In addition, as shown in Model 6 (see Table 2), the combined effect of all four team-level characteristics explained $29 \%$ of the variance in performance.

We next tested whether core and non-core characteristics were differentially related to team performance (Hypotheses 1B, 2B,

Table 1

Intercorrelations of Study Variables

\begin{tabular}{lcccccccr}
\hline \multicolumn{1}{c}{ Variable } & 1 & 2 & 3 & 4 & 5 & 6 & 7 & 8 \\
\hline 1. League & - & & & & & & \\
2. Career experience & .00 & - & & & & & \\
3. Team experience, $S D$ & .00 & .42 & - & & & & \\
4. Team experience, average & .01 & .41 & .85 & - & & & \\
5. Job-related skill $^{\text {6. Core resource allocation }}{ }^{\mathrm{a}}$ & .11 & .29 & .22 & .30 & - & & \\
7. Total resource allocation $^{\mathrm{a}}$ & .02 & .15 & -.06 & .05 & .02 & - & \\
8. Team performance & .11 & .31 & -.07 & -.20 & .20 & .04 & - & \\
\hline
\end{tabular}

Note. $\quad N=778$ at season level. Correlations greater than .07 are significant, $p<.05$. Correlations greater than .09 are significant, $p<.01$. League is dummy coded (American League $=0$, National League $=1$ ).

${ }^{a} N=498$ at season level for relationships with resource allocation. 
Table 2

Model Comparisons for Overall Effects

\begin{tabular}{|c|c|c|c|c|c|c|}
\hline Variable & Model 1 & Model 2 & Model 3 & Model 4 & Model 5 & Model 6 \\
\hline Intercept, $\beta_{0 \mathrm{ij}}$ & $-.020(.063)$ & $-.101(.082)$ & $-.104(.051)$ & $-.101(.070)$ & $-.063(.068)$ & $-.079(.045)$ \\
\hline League & & $.169(.116)$ & $.209(.072)$ & $.201(.099)$ & $.107(.096)$ & $.161(.065)$ \\
\hline Career experience & & & $.452(.033)$ & & & $.351(.035)$ \\
\hline Team experience $S D$, total & & & & $-.062(.066)$ & & $-.105(.060)$ \\
\hline Team experience average, total & & & & $.378(.065)$ & & $.199(.060)$ \\
\hline Job-related skill & & & & & $.347(.033)$ & $.221(.033)$ \\
\hline Variance, team level & $.080(.030)$ & $.066(.027)$ & $.009(.010)$ & $.041(.019)$ & $.036(.018)$ & $.004(.008)$ \\
\hline Variance, season level & $.926(.048)$ & $.928(.048)$ & $.774(.040)$ & $.845(.044)$ & $.825(.043)$ & $.711(.037)$ \\
\hline Total variance & 1.006 & .994 & .783 & .886 & .861 & .715 \\
\hline$-2 *$ loglikelihood & $2,182.239$ & $2,180.354$ & $2,016.808$ & $2,101.107$ & $2,080.557$ & $1,945.952$ \\
\hline$\%$ total variance explained & .00 & .01 & $.22^{* * *}$ & $.12^{* *}$ & $.14^{* *}$ & $.29^{* *}$ \\
\hline
\end{tabular}

Note. $\quad N=778$ at season level, 30 at team level. For variables, the first value in a cell is the beta coefficient, and the value in parentheses is the standard error.

*** $p<.01$.

and 3B) by testing a new set of models (presented in Table 3) and testing the differences in partial betas that resulted from these equations (Cohen and Cohen, 1983). First, the career experience of core role holders $(\beta=.332)$ was more strongly related to team performance than was the career experience of non-core role holders, $\beta=.183, t(774)=2.22, p<.05$; this result supported Hypothesis 1B. Second, having more variance on team experience was mildly worse for core roles $(\beta=-.107)$ than for non-core roles, $\beta=.028, t(774)=-1.30, n s$, whereas having higher mean levels of team experience was mildly better for core roles $(\beta=$ .290) than for non-core roles, $\beta=.151, t(774)=1.16$, $n s$. It is important to note that both of these values are nonsignificant according to traditional significance levels. Thus, Hypothesis 2B was not supported. Finally, job-related skill of core role holders ( $\beta=.286$ ) was more strongly related to team performance than was job-related skill of non-core role holders, $\beta=.206$, $t(1,774)=1.66, p<.05$. This result supported Hypothesis $3 \mathrm{~B}$.
These results highlight that the relationships between experience, job-related skill, and performance are greater when the characteristics are possessed by core role holders rather than non-core role holders. For the characteristics other than team experience, the beta coefficient for non-core role holders was at most $88 \%$ of the value of the beta coefficient for core role holders (i.e., the beta for job-related skill of non-core role holders was .176 , compared with a beta of .199 for core role holders).

Finally, we tested Hypothesis 4, which stated that teams with higher levels of core role allocation would have higher levels of performance. We again conducted HLM analyses. In addition to controlling for league, we controlled for total resource allocation (i.e., team payroll). It is reasonable to expect that teams that have a greater total set of resources will have higher levels of performance. By controlling for the total resource allocation, our measure of core resource allocation became a proxy for percentage of resources allocated to the core, rather than a measure of "richer" teams.

Table 3

Model Comparisons for Core and Non-Core Relationships

\begin{tabular}{|c|c|c|c|c|c|c|}
\hline Variable & Model 7 & Model 8 & Model 9 & Model 10 & Model 11 & Model 12 \\
\hline Intercept & $-.099(.050)$ & $-.103(.070)$ & $-.061(.066)$ & $-.075(.044)$ & $-.041(.092)$ & $-.049(.086)$ \\
\hline League & $.199(.071)$ & $.203(.099)$ & $.107(.094)$ & $.153(.064)$ & $.083(.128)$ & $.096(.120)$ \\
\hline Career experience, non-core & $.183(.038)$ & & & $.120(.040)$ & & \\
\hline Career experience, core & $.332(.038)$ & & & $.277(.039)$ & & \\
\hline Team experience $S D$, non-core & & $.028(.063)$ & & $.005(.057)$ & & \\
\hline Team experience $S D$, core & & $-.107(.066)$ & & $-.113(.060)$ & & \\
\hline Team experience average, non-core & & $.151(.067)$ & & $.049(.060)$ & & \\
\hline Team experience average, core & & $.290(.070)$ & & $.173(.065)$ & & \\
\hline Job-related skill, non-core & & & $.206(.033)$ & $.154(.031)$ & & \\
\hline Job-related skill, core & & & $.286(.034)$ & $.154(.033)$ & & \\
\hline Total resource allocation ${ }^{\mathrm{a}}$ & & & & & $.202(.047)$ & $-.281(.165)$ \\
\hline Core resource allocation ${ }^{a}$ & & & & & & $.514(.167)$ \\
\hline Variance, team level & $.008(.010)$ & $.041(.019)$ & $.033(.017)$ & $.002(.008)$ & $.073(.033)$ & $.058(.029)$ \\
\hline Variance, season level & $.769(.040)$ & $.843(.044)$ & $.823(.043)$ & $.705(.036)$ & $.868(.057)$ & $.858(.056)$ \\
\hline Total variance & .778 & .884 & .856 & .707 & .941 & .916 \\
\hline$-2 * \log$ likelihood & $2,011.204$ & $2,099.312$ & $2,077.625$ & $1,938.365$ & $1,368.574$ & $1,359.391$ \\
\hline$\%$ total variance explained & $.23^{* * *}$ & $.12^{* * *}$ & $.15^{* *}$ & $.30^{* * *}$ & $.06^{* * *}$ & $.09^{* * *}$ \\
\hline
\end{tabular}

Note. $\quad N=778$ at season level, 30 at team level. For variables, the first value in a cell in the beta coefficient and the value in parentheses is the standard error. ${ }^{\mathrm{a}} n=498$ at season level for relationships with salary.

*** $p<.01$. 
As shown in Model 11 (see Table 3), the addition of total resource allocation explained $6 \%$ of the variance in performance. Model 12 shows that the addition of core resource allocation significantly explained $3 \%$ of additional variance in team performance. This supported Hypothesis 4.

\section{Discussion}

The results of this study confirm that three experience and skill constructs are related to higher team performance. Consistent with our theory, the results show that it matters where these characteristics reside in the team. Core role holder characteristics (i.e., career experience and job-related skill) were more strongly related to performance than were the non-core role holder characteristics. Further, teams that invested more financial resources in core roles significantly outperformed those teams that did not leverage their assets as effectively.

\section{Theoretical Implications}

The theoretical contributions of this article can be broken into several categories. First, we provide an a priori definition of the strategic core role that can be used to identify components of a team. Second, the primary empirical finding of this research supports the argument that the strategic core matters, and this represents an important contribution to the literature on team role structures. In addition, our results suggest that resource allocation in many organizations may be inefficient and, thus, that firms may benefit from a reallocation of investments toward strategic core roles to achieve more efficient resource utilization. Finally, this research makes several contributions to the study of individual differences in teams.

Our article advances team theory by specifically presenting a tripartite a priori definition of the strategic core. Prior research on strategic cores, which has largely occurred at the organizational level, has defined the strategic core in terms of its contribution to performance. Such a definition is clearly tautological; yet, it is essential to recognize that this is not the definition developed in this article. Given the problems with past definitions, we chose to define the strategic core independently of team performance. We did this by suggesting that strategic core roles encounter more problems, have greater exposure to the tasks being performed, and are in a central position in the workflow. This definition implies nothing about the performance of the team. Instead, it concerns the structural aspects of team roles and their relative importance vis-à-vis the work the team performs. The quality of the performance of these roles and the ultimate impact of these roles on team performance constitute an entirely separate matter.

With strategic core roles thus defined, this article contributes to the study of teams by demonstrating that all roles are not created equally. That is, our study demonstrates that some roles in teams are more important than others. This finding stands in contrast to previous research on team composition, which has focused on differences between individual team members (individual attribute composition) rather than differences between roles (role composition). For example, in a recent meta-analysis on team personality composition, Bell (2007) noted that the popular approach of using Steiner's (1972) task categorization scheme to apply the "correct" aggregation technique to team member characteristics (e.g., using the lowest value on a team member characteristic to represent the "team" when the team is performing a conjunctive task) does not demonstrate stronger relationships between team member characteristics and team performance than does not matching the aggregation technique to the task being performed; in fact, use of this scheme generally results in finding weaker relationships with performance. This observation suggests that it may be time to utilize a new theoretical and empirical approach to team composition for team personality. Our article provides one such new avenue, as our theory and results demonstrate that one needs to consider parts of the whole (i.e., the roles within the team) rather than just the entire team (or specific members based on the task being performed) when examining team performance.

Directly building on these ideas, our research takes the next step by finding that investing more heavily in the core roles of teams results in significantly higher performance than does investing resources in non-core roles. From a theoretical perspective, much research has been done in strategy to explore how resources can be utilized by organizations to achieve optimal value (Majumdar, 1998). This finding adds an important extension to this work by examining how resources are used in addition to the study of basic resource characteristics.

One implication of teams leveraging the core is that this practice should introduce variance in resource allocation within the team. That is, in terms of salary, leveraging the core suggests that some team members will be compensated very well, whereas other members will not be compensated as highly. A large amount of variance on salary within the team will result. This suggests that variance in pay will predict team performance but "only under the conditions in which variance is derived from a focus on the critical roles." ${ }^{3}$ That is, having variance on salary that is spread across the core and non-core roles (e.g., the two highest paid team members on a baseball team are the third baseman and a starting pitcher, whereas the two lowest paid players are the second baseman and another starting pitcher), or paying all of the non-core players highly and all of the core players less, should result in lower overall team performance.

For their part, organizations are coming to recognize the value of specific team roles. For example, in the recent negotiated collective bargaining agreement between General Motors and the United Auto Workers, there is "a second tier of compensation for jobs that GM and the UAW have agreed are 'non-core' production jobs. This is expected to include many positions in which workers do not have their hands on a vehicle in the assembly process" ("New Details," 2007). The agreement will increase pay variance in teams. However, it also runs the risk of producing animosity between team members, as certain roles (and the members who occupy these roles) will now be identified as being less valuable to the team. Future research should investigate the implications on interpersonal dynamics within the team that result from making strategic decisions on core role allocation.

Finally, this research contributes to the study of individual differences in teams by demonstrating that three individual difference constructs (two experience and one skill) related to

\footnotetext{
${ }^{3}$ We thank an anonymous reviewer for this idea. In particular, the specific quoted statement was mentioned to us by the reviewer during the review process.
} 
performance. Although most previous team-level research has examined only one of these constructs at a time, our study demonstrates the complexity of experience (Quiñones et al., 1995; Tesluk \& Jacobs 1998). ${ }^{4}$

\section{Applied Implications}

Our research provides guidance for team staffing. Whereas most studies of team staffing have utilized the individual attribute composition approach (Morgeson \& Humphrey, 2008; Morgeson, Reider, \& Campion, 2005), our findings suggest that it is particularly important for managers to take role composition issues into account when they make placement decisions in teams and, thus, that managers place priority on the strategically core roles when they build or change teams.

In addition, our findings on the relevance of core roles suggest a new, theoretically based methodology for investigating teams. For example, there has been extensive speculation about the relationship between team personality and performance, though the results are equivocal (Bell, 2007). As recent research has called for an investigation of more complex conceptualizations of team personality configurations (Humphrey, Hollenbeck, Meyer, \& Ilgen, 2007), one may suspect that the nonsignificant results are not the function of weak theory but rather that researchers have not investigated where personality resides within the team. Consider two teams with equal mean levels of conscientiousness. On Team X, the core role holders possess high levels of conscientiousness, whereas the non-core role holders possess low levels of conscientiousness. On Team Y, the composition is flipped: The core role holders possess low levels of conscientiousness, and the non-core role holders possess high levels of conscientiousness. If we used the traditional individual attribute composition approach, in which the mean level (or even the variance) on team conscientiousness is related to team performance, there would be no relationship between conscientiousness and team performance. However, if our study followed the theoretical arguments presented herein, we would expect Team $X$ to have higher levels of team performance than would Team Y, as the more critical role is staffed with the most hardworking members. Following this logic, we expect that areas such as motivation and performance effectiveness would benefit from studies of whether a strategic core exists.

\section{Limitations, Generalizability, and Future Research}

The focus of the team may serve as a boundary condition. When a team is task focused, roles that have more exposure to tasks being performed and that encounter more problems should be more critical for team performance. In contrast, a strategic core may be irrelevant in a team that is primarily focused on non-task outcomes, such as cohesion or the maintenance of relationships within the team (i.e., the more social aspects of teamwork; Mumford et al., 2006), as the characteristics of a strategic core are not likely to be related to these outcomes.

A possible limitation of our study is that this set of results may be idiosyncratic to the baseball context. However, we believe that there are several reasons why this not a concern. First, just as organizational teams often have long life spans, baseball teams operate continuously for 7 months. Second, baseball teams are intense action teams, in that they work together for $3 \mathrm{hr}$ a day, 6 days a week. Third, baseball teams have numerous performance episodes with situationally relevant outcomes. Individual baseball players, like members of organizational teams, are rewarded on the basis of both their own and the team's performance; they can lose their job if they no longer perform to an acceptable level. Fourth, other researchers have used this context to examine organizational phenomena and have produced relationships replicable in other contexts (Hofmann et al., 1992; Pfeffer \& Davis-Blake, 1986).

In this study, we specifically focused on experience and skill, as there is a great deal of evidence that they impact individual level performance. However, other characteristics, such as demography or personality, are important for team performance (Homan et al., in press). Future research should test the strategic core proposition with other characteristics and in other contexts. In addition, future research should examine experience and job-related skill with other team types. In this study, we focused on one kind of action team (i.e., baseball teams). However, Sundstrom et al. (1990) suggested that there are three other team types: advice/ involvement, production/service, and project/development. Such teams differ on work-team differentiation, external integration, work cycles, and typical outputs. These distinctions might lead to the differential impact of the experience and skill constructs examined in this article.

Finally, the level of interdependence between roles may serve as a boundary condition. Delery and Shaw (2001) suggested that high interdependence between employee groups within a firm limits the relevance of any single group and thus necessitates the prioritization of the groups. That is, if groups are reciprocally interdependent, each of them is reliant on the outputs of other groups in order to perform its tasks. Within teams, it may be that a strategic core is less relevant when a team has very high levels of interdependence between the tasks associated with core and non-core roles. Essentially, the more tightly connected two roles are, the lower the chance that these roles will be different on the extent to which they are core for the team.

\footnotetext{
${ }^{4}$ Tesluk and Jacobs (1998) also suggested that experience in challenging situations (i.e., the quality and richness of experience, rather than just the quantity) is an important dimension of experience, as challenging situations provide both the opportunity and motivation to learn (McCauley, Ruderman, Ohlott, \& Morrow, 1994). We tested this dimension of experience by creating a variable that represented the number of postseason games played (i.e., divisional series, league championship series, and the World Series). The results of our analyses showed that experience in challenging situations demonstrated a direct effect on performance $\left(\beta=.397, \Delta R^{2}=.18\right.$, $p<.05)$ and, more important, that the experience in challenging situations of core role holders $(\beta=$. 372) was more strongly related to team performance than was the experience in challenging situations of non-core role holders, $\beta=$. 051, $t(774)=3.39, p<.05$. These results demonstrate that experience in challenging situations for non-core versus core role holders had the most divergent values of any of the individual differences in our study, as the non-core beta coefficient reached only $14 \%$ of the magnitude of the core coefficient. Given the strength of this relationship and Tesluk and Jacobs's (1998) suggestion that experience quality has not been sufficiently studied, these results suggest that future research should integrate experience quality into models that examine individual differences in teams.
} 


\section{References}

Abramis, D. J. (1994). Work role ambiguity, job satisfaction, and job performance: Meta-analyses and review. Psychological Reports, 75, $1411-1433$

Ancona, D. G., \& Caldwell, D. F. (1992). Bridging the boundary: External activity and performance in organizational teams. Administrative Science Quarterly, 37, 634-665.

Austin, J. R. (2003). Transactive memory in organizational groups: The effects of content, consensus, specialization, and accuracy on group performance. Journal of Applied Psychology, 88, 866-878.

Bachrach, D. G., Bendoly, E., \& Podsakoff, P. M. (2001). Attributions of the "causes" of group performance as an alternative explanation of the relationship between organizational citizenship behavior and organizational performance. Journal of Applied Psychology, 86, 1285-1293.

Bales, R. F. (1950). Interaction process analysis: A method for the study of small groups. Cambridge, MA: Addison-Wesley.

Barker, J. R. (1993). Tightening the iron cage: Concertive control in self-managing teams. Administrative Science Quarterly, 38, 408-437.

Barney, J. B. (1991). Firm resources and sustained competitive advantage. Journal of Management, 17, 99-120.

Barrick, M. R., Stewart, G. L., Neubert, M. J., \& Mount, M. K. (1998). Relating member ability and personality to work-team processes and team effectiveness. Journal of Applied Psychology, 83, 377-391.

Beersma, B., Hollenbeck, J. R., Humphrey, S. E., Moon, H., Conlon, D. E., \& Ilgen, D. R. (2003). Cooperation, competition, and team performance: Towards a contingency approach. Academy of Management Journal, 46, 572-590.

Belbin, R. M. (1993). Team roles at work. Oxford, England: ButterworthHeinemann

Bell, S. T. (2007). Deep-level composition variables as predictors of team performance: A meta-analysis. Journal of Applied Psychology, 92, 595-615.

Berman, S. L., Down, J., \& Hill, C. W. L. (2002). Tacit knowledge as a source of competitive advantage in the National Basketball Association. Academy of Management Journal, 45, 13-31.

Biddle, B. J. (1979). Role theory: Expectations, identities, and behavior. New York: Academic Press.

Brass, D. J. (1984). Being in the right place: A structural analysis of individual influence in an organization. Administrative Science Quarterly, 29, 518-539.

Bunderson, J. S. (2003). Recognizing and utilizing expertise in work groups: A status characteristics perspective. Administrative Science Quarterly, 48, 557-591.

Chan, D. (1998). Functional relations among constructs in the same domain at different levels of analysis: A typology of composition models. Journal of Applied Psychology, 83, 234-246.

Chen, G., Bliese, P. D., \& Mathieu, J. E. (2005). Conceptual framework and statistical procedures for delineating and testing multilevel theories of homology. Organizational Research Methods, 8, 375-409.

Chen, G., Kirkman, B. L., Kanfer, R., Allen, D., \& Rosen, B. (2007). A multilevel study of leadership, empowerment, and performance in teams. Journal of Applied Psychology, 92, 331-346.

Cohen, J., \& Cohen, P. (1983). Applied multiple regression/correlation analysis for the behavioral sciences. Mahwah, NJ: Erlbaum.

Cummings, T. G. (1978). Self-regulating work groups: A socio-technical synthesis. Academy of Management Review, 3, 625-634.

Delery, J. E., \& Shaw, J. D. (2001). The strategic management of people in work organizations: Review, synthesis, and extension. In G. R. Ferris (Ed.), Research in personnel and human resource management (Vol. 20, pp. 165-197). New York: Elsevier Science.

Emery, F. E., \& Trist, E. L. (1969). Socio-technical systems. In F. E. Emery (Ed.), Systems thinking (pp. 281-296). London: Penguin Books.

Freeman, L. C. (1979). Centrality in networks: I. Conceptual clarification. Social Networks, 1, 215-239.
Friedkin, N. E. (1991). Theoretical foundations for centrality measures. American Journal of Sociology, 96, 1478-1504.

Gladstein, D. L. (1984). Groups in context: A model of task group effectiveness. Administrative Science Quarterly, 29, 499-517.

Goff, B. L., \& Tollison, R. D. (1990). Sports as economics. In B. L. Goff \& R. D. Tollison (Eds.), Sportometrics (pp. 3-14). College Station: Texas A\&M University Press.

Hackman, J. R. (1987). The design of work teams. In J. W. Lorsch (Ed.), Handbook of organizational behavior (pp. 315-342). Englewood, NJ: Prentice-Hall.

Harrison, D. A., \& Klein, K. J. (2007). What's the difference? Diversity constructs as separation, variety, or disparity in organizations. Academy of Management Review, 32, 1199-1229.

New details of deal emerge. (2007, September 26). Detroit Free Press. Retrieved from http://www.freep.com/apps/pbcs.dll/article?AID =/ 20070926/BUSINESS01/70926013

Hofmann, D. A., Jacobs, R., \& Gerras, S. J. (1992). Mapping individual performance over time. Journal of Applied Psychology, 77, 185-195.

Hollenbeck, J. R., Ilgen, D. R., Sego, D. J., Hedlund, J., Major, D. A., \& Phillips, J. (1995). Multilevel theory of team decision making: Decision performance in teams incorporating distributed expertise. Journal of Applied Psychology, 80, 292-316.

Hollenbeck, J. R., Moon, H., Ellis, A., West, B., Ilgen, D. R., Sheppard, L., et al. (2002). Structural contingency theory and individual differences: Examination of external and internal person-team fit. Journal of Applied Psychology, 87, 599-606.

Homan, A. C., Hollenbeck, J. R., Humphrey, S. E., van Knippenberg, D., Ilgen, D. R., \& Van Kleef, G. A. (in press). Facing differences with an open mind: Openness to experience, salience of intra-group differences, and performance of diverse work groups. Academy of Management Journal.

House, R. J., Rousseau, D. M., \& Thomas-Hunt, M. (1995). The meso paradigm: A framework for the integration of micro and macro organizational behavior. In L. L. Cummings \& B. M. Staw (Eds.), Research in organizational behavior (Vol. 21, pp. 1-38). Greenwich, CT: JAI Press.

Humphrey, S. E., Hollenbeck, J. R., Meyer, C. J., \& Ilgen, D. R. (2002), Hierarchical team decision making. In G. R. Ferris \& J. J. Martocchio (Eds.), Research in personnel and human resources management (Vol. 21, pp. 175-214). Amsterdam: Elsevier Science.

Humphrey, S. E., Hollenbeck, J. R., Meyer, C. J., \& Ilgen, D. R. (2007). Trait configurations in self-managed teams: A conceptual examination of the use of seeding to maximize and minimize trait variance in teams. Journal of Applied Psychology, 92, 885-892.

Humphrey, S. E., Nahrgang, J. D., \& Morgeson, F. P. (2007). Integrating motivational, social, and contextual work design features: A metaanalytic summary and theoretical extension of the work design literature. Journal of Applied Psychology, 92, 1332-1356.

Hunter, J. E., \& Hunter, R. F. (1984). Validity and utility of alternative predictors of job performance. Psychological Bulletin, 96, 72-98.

Huselid, M. A., Beatty, R. W., \& Becker, B. E. (2005). "A players" or "A positions"? The strategic logic of workforce management. Harvard Business Review, 83, 110-117.

Ilgen, D. R., Hollenbeck, J. R., Johnson, M. D., \& Jundt, D. K. (2005). Teams in organizations: From input-process-output models to IMOI models. Annual Review of Psychology, 56, 517-543.

James, B. (1982). 1982 Bill James baseball abstract. New York: Ballantine Books.

James, B., \& Henzler, J. (2002). Win shares. Morton Grove, IL: STATS.

Kahn, L. M. (1993). Managerial quality, team success, and individual player performance in major league baseball. Industrial and Labor Relations Review, 531-547.

Katz, D., \& Kahn, R. L. (1978). The social psychology of organizations (2nd ed.). New York: Wiley. 
Keidel, R. W. (1987). Team sports models as a generic organizational framework. Human Relations, 40, 591-612.

Keil, M., Mann, J., \& Rai, A. (2000). Why software projects escalate: An empirical analysis and test of four theoretical models. MIS Quarterly, 24, 631-664.

Kim, P. H. (1997). When what you know can hurt you: A study of experiential effects on group discussion and performance. Organizational Behavior and Human Decision Processes, 69, 165-177.

Klein, K. J., Dansereau, F., \& Hall, R. J. (1994). Level issues in theory development, data collection, and analysis. Academy of Management Review, 19, 195-229.

Klein, K. J., Ziegert, J. C., Knight, A. P., \& Xiao, Y. (2006). Dynamic delegation: Shared, hierarchical, deindividualized leadership in extreme action teams. Administrative Science Quarterly, 51, 590-621.

Kozlowski, S. J., \& Klein, K. J. (2000). A multilevel approach to theory and research in organizations: Contextual, temporal, and emergent processes. In K. J. Klein \& S. J. Kozlowski (Eds.), Multilevel theory, research, and methods in organizations (pp. 3-90). San Francisco: Jossey-Bass.

Lahman, S. (2004). The baseball archive [Database]. Retrieved March 15, 2004, from http://www.baseball1.com/statistics/

Lance, C. E., \& Bennett, W., Jr. (2000). Replication and extension of models of supervisory job performance ratings. Human Performance, 13, 139-158.

Lawrence, P. R., \& Lorsch, J. W. (1969). Developing organizations: Diagnosis and analysis. Reading, MA: Addison-Wesley.

LePine, J. A., Hollenbeck, J. R., Ilgen, D. R., \& Hedlund, J. (1997). Effects of individual differences on the performance of hierarchical decisionmaking teams: Much more than g. Journal of Applied Psychology, 82, 803-811.

Lewis, K. (2003). Measuring transactive memory systems in the field: Scale development and validation. Journal of Applied Psychology, 88, 587-604.

Lewis, M. (2003). Moneyball: The art of winning an unfair game. New York: Norton.

Majumdar, S. (1998). On the utilization of resources: Perspectives from the U.S. telecommunications industry. Strategic Management Journal, 19, 809-831.

Mathieu, J. E., Heffner, T. S., Goodwin, G. F., Salas, E., \& CannonBowers, J. A. (2000). The influence of shared mental models on team process and performance. Journal of Applied Psychology, 85, 273-283.

McCauley, C. D., Ruderman, M. N., Ohlott, P. J., \& Morrow, J. E. (1994). Assessing the developmental components of managerial jobs. Journal of Applied Psychology, 79, 544-560.

McDaniel, M. A., Schmidt, F. L., \& Hunter, J. E. (1988). Job experience correlates of job performance. Journal of Applied Psychology, 73, 327-330.

Miller, D. L. (2001). Reexamining teamwork KSAs and team performance. Small Group Research, 32, 745-766.

Mohammed, S., Mathieu, J. E., \& Bartlett, A. L. (2002). Technicaladministrative task performance, leadership task performance, and contextual task performance: Considering the influence of team- and taskrelated composition variables. Journal of Organizational Behavior, 23, 795-814.

Moon, H., Hollenbeck, J. R., Humphrey, S. E., Ilgen, D. R., West, B. J., \& Ellis, A. P. J. (2004). Asymmetric adaptability: Dynamic team structures as one-way streets. Academy of Management Journal, 47, 681-695.

Morgeson, F. P., Delaney-Klinger, K. A., \& Hemingway, M. A. (2005). The importance of job autonomy, cognitive ability, and job-related skill for predicting role breadth and job performance. Journal of Applied Psychology, 90, 399-406.

Morgeson, F. P., \& Hofmann, D. A. (1999). The structure and function of collective constructs: Implications for multilevel research and theory development. Academy of Management Review, 24, 249-265.
Morgeson, F. P., \& Humphrey, S. E. (2008). Job and team design: Toward a more integrative conceptualization of work design. In J. Martocchio (Ed.), Research in personnel and human resource management (Vol. 27, pp. 39-92). Bradford, England: Emerald Group.

Morgeson, F. P., Reider, M. H., \& Campion, M. A. (2005). Selecting individuals in team settings: The importance of social skills, personality characteristics, and teamwork knowledge. Personnel Psychology, 58, 583-611.

Mumford, T. V., Campion, M. A., \& Morgeson, F. P. (2006). Situational judgment in work teams: A team role typology. In J. A. Weekley \& R. E. Ployhart (Eds.), Situational judgment tests: Theory, measurement, and application (pp. 319-343). Mahwah, NJ: Erlbaum.

Mumford, T. V., Van Iddekinge, C. H., Morgeson, F. P., \& Campion, M. A. (2008). The team role test: Development and validation of a team role knowledge situational judgment test. Journal of Applied Psychology, 93, 250-267.

Neuman, G. A., \& Wright, J. (1999). Team effectiveness: Beyond skills and cognitive ability. Journal of Applied Psychology, 84, 376-389.

Pearsall, M. J., \& Ellis, A. P. J. (2006). The effects of critical team member assertiveness on team performance and satisfaction. Journal of Management, 32, 575-594.

Pfeffer, J., \& Davis-Blake, A. (1986). Administrative succession and organizational performance: How administrator experience mediates the succession effect. Academy of Management Journal, 29, 72-83.

Quiñones, M. A., Ford, J. K., \& Teachout, M. S. (1995). The relationship between work experience and performance: A conceptual and metaanalytic review. Personnel Psychology, 48, 887-910.

Rasbash, J., Steele, F., Browne, W., \& Prosser, B. (2004). A user's guide to MLwiN version 2.0. London: Institute of Education.

Raudenbush, S. W., \& Bryk, A. S. (2002). Hierarchical linear models: Applications and data analysis methods. Thousand Oaks, CA: Sage.

Rentsch, J. R., \& Klimoski, R. J. (2001). Why do "great minds" think alike?: Antecedents of team member schema agreement. Journal of Organizational Behavior, 22, 107-120.

Retrosheet. (2004). Retrosheet database. Retrieved March 15, 2004, from http://www.retrosheet.org/boxesetc/

Rousseau, D. M. (1985). Issues of level in organizational research: Multilevel and cross-level perspectives. In B. M. Staw \& L. L. Cummings (Eds.), Research in organizational behavior (pp. 1-37). Greenwich, CT: JAI Press.

Salas, E., Rozell, D., Mullen, B., \& Driskell, J. E. (1999). The effect of team building on performance: An integration. Small Group Research, 30, 309-329.

Schmidt, F. L., \& Hunter, J. E. (1998). The validity and utility of selection methods in personnel psychology: Practical and theoretical implications of 85 years of research findings. Psychological Bulletin, 124, 262-274.

Schmidt, F. L., Hunter, J. E., \& Outerbridge, A. N. (1986). Impact of job experience and ability on job knowledge, work sample performance, and supervisory ratings of job performance. Journal of Applied Psychology, $71,432-439$.

Seers, A., Petty, M. M., \& Cashman, J. F. (1995). Team-member exchange under team and traditional management: A naturally occurring quasiexperiment. Group and Organization Management, 20, 18-38.

Sparrowe, R. T., Liden, R. C., Wayne, S. J., \& Kraimer, M. L. (2001). Social networks and the performance of individuals and groups. Academy of Management Journal, 44, 316-325.

Staw, B. M., \& Hoang, H. (1995). Sunk costs in the NBA: Why draft order affects playing time and survival in professional basketball. Administrative Science Quarterly, 40, 474-494.

Steiner, I. D. (1972). Group process and productivity. New York: Academic Press.

Stewart, G. L., Fulmer, I. S., \& Barrick, M. R. (2005). An exploration of 
member roles as a multilevel linking mechanism for individual traits and team outcomes. Personnel Psychology, 58, 343-365.

Sundstrom, E., de Meuse, K. P., \& Futrell, D. (1990). Work teams: Applications and effectiveness. American Psychologist, 45, 120-133.

Tesluk, P. E., \& Jacobs, R. R. (1998). Toward an integrated model of work experience. Personnel Psychology, 51, 321-355.

Tuckman, B. W. (1965). Developmental sequence in small groups. Psychological Bulletin, 63, 384-399.

Tziner, A., \& Eden, D. (1985). Effects of crew composition on crew performance: Does the whole equal the sum of its parts? Journal of Applied Psychology, 70, 85-93.

Wegner, D. M. (1986). Transactive memory: A contemporary analysis of the group mind. In B. Mullen \& G. R. Goethals (Eds.), Theories of group behavior (pp. 185-205). New York: Springer-Verlag.

Williams, W. M., \& Sternberg, R. J. (1988). Group intelligence: Why some groups are better than others. Intelligence, 12, 351-377.

Wolfe, R., Weick, K. E., Usher, J., Terborg, J., Poppo, L., Murrell, A., et al. (2005). Sport and organizational studies: Exploring synergy. Journal of Management Inquiry, 14, 182-210.

Received July 9, 2007

Revision received May 11, 2008

Accepted May 27, 2008

\section{ORDER FORM}

Start my 2009 subscription to the Journal of Applied Psychology ISSN:0021-9010

$\$ 98.00$

$\$ 249.00$

$\$ 715.00$

APA MEMBER/AFFILIATE

INDIVIDUAL NONMEMBER

INSTITUTION

In DC add 5.75\% / In MD add 6\% sales tax

TOTAL AMOUNT DUE

Subscription orders must be prepaid. Subscriptions are on a calendar year basis only. Allow 4-6 weeks for delivery of the first issue. Call for international subscription rates.

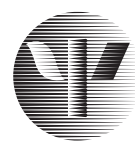

AMERICAN PSYCHOLOGICAL ASSOCIATION

\section{SEND THIS ORDER FORM TO}

American Psychological Association

Subscriptions

750 First Street, NE

Washington, DC 20002-4242

Call 800-374-2721 or 202-336-5600

Fax 202-336-5568 :TDD/TTY 202-336-6123

For subscription information,

e-mail:subscriptions@apa.org $\square$ Check enclosed (make payable to APA)

Charge my: $\square$ Visa $\square$ MasterCard $\square$ American Express

Cardholder Name

Card No. _ Exp. Date

Signature (Required for Charge)

\section{Billing Address}

Street

City State Zip

Daytime Phone

E-mail

\section{Mail To}

Name

Address

City _ State _ Zip

APA Member \#
Zip 